\title{
Assessment of the Feelings and Attitudes of Children towards Their Dentist and Their Association with Oral Health
}

\author{
Aslı Patır Münevveroğlu, Beyza Ballı Akgöl, and Tuğba Erol \\ Department of Pedodontics, Faculty of Dentistry, Istanbul Medipol University, 34083 Istanbul, Turkey \\ Correspondence should be addressed to Aslı Patır Münevveroğlu; apatir@medipol.edu.tr
}

Received 13 August 2013; Accepted 3 October 2013; Published 27 March 2014

Academic Editors: C. Lekic, G. H. Sperber, and D. Wray

Copyright (C) 2014 Aslı Patır Münevveroğlu et al. This is an open access article distributed under the Creative Commons Attribution License, which permits unrestricted use, distribution, and reproduction in any medium, provided the original work is properly cited.

\begin{abstract}
This study assessed the feelings and attitudes of children toward their dentists and their association with oral health. Methods. A questionnaire designed to evaluate the attitudes of children toward dentists and preferences was completed by 200 children and their families. In addition, the children were examined and the World Health Organization (WHO) method was used to obtain $\mathrm{dmft}$ and DMFT scores. Results. The mean $\mathrm{dmft}$ and DMFT scores were $3.52 \pm 2.44$ and $1.35 \pm 1.29$, respectively. Of the children, $92.5 \%$ reported that they had visited a dentist before. Of the children who had visited dentists, approximately $71.5 \%$ reported that they enjoyed their visits. Of the children, $84 \%$ preferred female dentists, $76.5 \%$ preferred dentists that wore a colored coat, and $63 \%$ preferred a decorated dental clinic over a plain clinic. The mean $\mathrm{dmft}$ and DMFT values of children who were afraid of dentists were significantly higher than those of children who were not $(P<0.01$ and $P<0.05$, resp.). Conclusion. Children have strong perceptions and preferences regarding the appearance of their dentists and dental clinics. The results of this study might help dentists to improve their delivery of care.
\end{abstract}

\section{Introduction}

In dental practice, most children do not cooperate during dental procedures and sometimes it is very difficult to manage a child in a dental clinic. These management difficulties are related not only to the technical procedures involved, but also to the different emotional upsets experienced by children. The most common emotional upsets seen during dental treatment are anxiety and fear, which might originate from a previous traumatic experience in the dental office or during hospitalization for other reasons $[1,2]$.

Dental anxiety and fear of dental treatment in children are recognized in many countries as a public health dilemma [3]. The terms dental fear and dental anxiety are often used synonymously [4] and are considered to be the main reason for behavior management problems and avoidance of dental care [5]. These problems sometimes require replacement of conventional treatment with more complicated alternatives, such as sedation or general anesthesia [6]. Surveys indicate that $5-6 \%$ of the population and $16 \%$ of school-age children fear dentists [7]. Indeed, children with active caries are more afraid than other children due to negative treatment experiences [8]. Alvesalo et al. reported that boys with a DMFT score $\geq 1$ had a significantly higher mean dental fear than those who were caries-free [9].

It is important for dentists to establish a friendly relationship with patients, especially children, to reduce patient fear and achieve efficient dental treatment. Children who have positive interactions with their dentist will be less likely to develop a fear of dentists and will experience less anxiety. As a result, they will be more likely to visit the dentist and will have better dental health [7].

We assessed feelings and attitudes of children toward their dentists and their association with oral health.

\section{Materials and Methods}

Data were obtained from a sample of children using a questionnaire developed by AlSarheed [7]. The study protocol received institutional approval from the Ethics Committee of Istanbul Medipol University, Istanbul (B.30.2.IMÜ.O.05.05GOKAEK-05). The study group comprised children aged 612 years attending the Department of Pedodontics, Faculty 
of Dentistry, Istanbul Medipol University for routine followup. The questionnaire was administered to 200 children, comprising 98 (49\%) girls and 102 (51\%) boys. Consent was obtained from parents/guardians to participate in the study. 200 children were requested to participate in the study to obtain 200 completed questionnaires. The response rate was $100 \%$.

The questionnaire included seven items designed to assess children's perceptions of their dentists. The subjects were asked if they had visited the dentist before and if there were any physicians in the family. They were also asked to describe the attitudes of siblings regarding dental visits. In addition, each child was asked to choose pictures that indicated their preference regarding dentist gender, attire, and protective equipment, and the design of the dental clinic.

The clinical examinations were performed by one examiner (TE) using disposable mouth mirrors for indirect vision of the lingual areas of the teeth and torchlight. A community periodontal index (WHO-BPE probe/G21) probe was used to confirm visual evidence of caries on the occlusal, buccal, and lingual surfaces. During the examination, the children were seated on a chair. Gauze pads were used to clean and dry the teeth surfaces before the examination. A schedule for data collection was prepared in advance and 40-50 children were examined each day. A dental surgeon sat close to the examiner to hear and record the codes. The World Health Organization (WHO) criteria (1997) were used to diagnose caries [10].

2.1. Statistical Analysis. The questionnaire data were coded and entered into SPSS ver. 15.0 (SPSS, Chicago, IL, USA) for statistical analysis. The conformation of parameters to normal distributions was evaluated using the KolmogorovSmirnov test. Descriptive and analytic approaches were used in the data analysis. The chi-square test, Mann-Whitney $U$ test, and Student's $t$-test were used to determine relationships among variables. Spearman's rho correlation was used to evaluate parameters that were distributed normally.

\section{Results}

The study group comprised 200 children aged 6-12 (mean $9.41 \pm 1.48$ ) years attending the Department of Pedodontics, Faculty of Dentistry, Istanbul Medipol University for routine visits, including 98 (49\%) girls and 102 (51\%) boys. The mean $\mathrm{dmft}$ and DMFT scores were $3.52 \pm 2.44$ and $1.35 \pm 1.29$, respectively.

Of the study children, $92.5 \%$ had visited a dentist before. The children's responses to their previous dental experience are summarized in Table 1 . The majority of children $(71.5 \%)$ reported that they enjoyed their visit to the dentist. The perceptions of children who had a physician in the family were significantly different from those of children who did not. Approximately $26 \%$ of the children reported that a sibling had a pleasant perception of their visit to a dentist.

The children's perceptions of their dentists are summarized in Table 2 . Approximately $84 \%$ of the children preferred to be treated by a female dentist; $76.5 \%$ preferred their dentist to wear a colored coat instead of a white one. This preference
TABLE 1: Summary of the responses of the children to their previous dental experience.

\begin{tabular}{lcc}
\hline Questions & Response & Number (\%) \\
\hline Have you been to a dentist before? & Yes & $185(92.5)$ \\
& No & $15(7.5)$ \\
\hline How did you feel during dental & Liked it & $143(71.5)$ \\
treatment? & Do not like it & $42(28.5)$ \\
\hline \multirow{2}{*}{ Is there a physician in your family? } & Yes & $13(6.5)$ \\
& No & $187(93.5)$ \\
\hline How did your sibling feel when & Liked it & $52(26)$ \\
he/she visited a dentist & Did not like it & $148(74)$ \\
\hline
\end{tabular}

TABLE 2: Summary of the perceptions of children of their dentists.

\begin{tabular}{lcc}
\hline Questions & Response & Number (\%) \\
\hline $\begin{array}{l}\text { Do you prefer to be treated by } \\
\text { a male or female dentist? }\end{array}$ & Male & $16 \%$ \\
\hline Which outfit do you prefer? & Female & $84 \%$ \\
\hline & Colored coat & $76.5 \%$ \\
& White coat & $23.5 \%$ \\
\hline \multirow{2}{*}{ Which dentist do you prefer? } & Protective glasses & $1 \%$ \\
& Mask & $70.5 \%$ \\
& Mask and protective & $8.5 \%$ \\
\hline
\end{tabular}

was significant. Of the children, $20 \%$ preferred their dentist not to wear protective equipment. When shown pictures of the same dentist wearing a mask or protective eye glasses or both the mask and eyewear, $8.5 \%$ of the children picked the picture of the individual wearing both pieces of protective gear as the dentist they would like to be treated by, while $1 \%$ chose the picture of the dentist wearing eye glasses and $70.5 \%$ chose the picture of the dentist wearing a mask.

When the children were asked to choose between pictures of undecorated and decorated dental clinics as the clinic they would like to be treated in, $76.5 \%$ selected the decorated dental clinic. However, there was no significant difference between the age groups $(P<0.05)$.

Children described several causes of fear related to visits to the dentist's office. These fears were related to injection (60\%), tooth extraction $(50 \%)$, restorations $(3.6 \%)$, and the sight of dental instruments (40\%).

The children who were afraid of the dentist were significantly younger than those who were not $(P<0.01)$. There was no significant difference in the mean age of the children according to dental clinic perception $(P>0.05)$ (Table 3$)$.

The distributions of the $\mathrm{dmft}$ and DMFT scores by gender and fear of dentists are shown in Table 4. There was no significant difference between the mean $\mathrm{dmft}$ and DMFT scores according to gender $(P>0.05)$. The mean $\mathrm{dmft}$ and DMFT scores of children with dental fear were significantly higher than those of those who did not $(P<0.01, P<0.05)$. 
TABLE 3: Distributions of dental fear and perception of the dental clinic according to age.

\begin{tabular}{lc}
\hline & $\begin{array}{c}\text { Age } \\
\text { Mean } \pm \text { SD }\end{array}$ \\
\hline Dental fear & \\
Yes & $8.64 \pm 1.54$ \\
No & $9.69 \pm 1.36$ \\
$P$ & $\mathbf{0 . 0 0 1}^{* *}$ \\
Perception & \\
Undecorated clinic & $9.74 \pm 1.58$ \\
Decorated clinic & $9.31 \pm 1.44$ \\
$P$ & $\mathbf{0 . 0 8 2}$ \\
\hline
\end{tabular}

Student's $t$-test ${ }^{* *} P<0.01$.

TABLE 4: Distribution of dmft and DMFT scores according to gender and dental fear.

\begin{tabular}{ccc}
\hline & $\begin{array}{c}\mathrm{dmft} \\
\text { Mean } \pm \text { SD (median) }\end{array}$ & $\begin{array}{c}\text { DMFT } \\
\text { Mean } \pm \text { SD (median) }\end{array}$ \\
\hline Gender & & \\
Female & $3.45 \pm 2.41(4)$ & $1.36 \pm 1.34(1)$ \\
Male & $3.59 \pm 2.48(4)$ & $1.34 \pm 1.25(1)$ \\
$P$ & $\mathbf{0 . 8 2 6}$ & $\mathbf{0 . 9 9 7}$ \\
Dental fear & & \\
Yes & $4.87 \pm 2.37(5)$ & $1.11 \pm 1.43(0)$ \\
No & $3.03 \pm 2.29(3)$ & $1.44 \pm 1.23(1)$ \\
$P$ & $\mathbf{0 . 0 0 1 * *}$ & $\mathbf{0 . 0 4 4}^{*}$
\end{tabular}

Mann-Whitney $U$ test ${ }^{*} P<0.05,{ }^{* *} P<0.01$.

In this study, $84 \%$ of the children preferred to be treated by a female dentist; this was not affected by the gender of the child $(P>0.01)$ (Table 5).

\section{Discussion}

Sitting on a dental chair under bright lights and hearing the noise coming from the equipment can be an unpleasant experience for children. A pediatric dental office should be designed in such a way that children can feel comfortable as they wait for their appointment. The children in this study favored a decorated dental clinic over a plain clinic. This concurs with the report by AlSarheed, in which $63 \%$ of the children selected the decorated clinic [7].

Physical appearance is a factor in a person's choice and plays an important role in the development of the physicianpatient relationship. Mistry and Tahmassebi assessed the attitudes of children and parents towards dental attire and found that parents favored traditional dress as it gives an air of professionalism [11]. AlSarheed indicated that children prefer their dentist to wear the traditional formal attire with a white coat as they see it as a symbol of healing [7]. This finding supports the report by McCarthy et al. [12] who found that children are not afraid of a physician in a white coat. In our study, however, $76.5 \%$ of the children preferred their dentist to wear a colored coat instead of white one.
TABLE 5: Perception of dentist gender according to the gender of the children.

\begin{tabular}{lccc}
\hline & $\begin{array}{c}\text { Girls } \\
n(\%)\end{array}$ & $\begin{array}{c}\text { Boys } \\
n(\%)\end{array}$ & $P$ \\
\hline $\begin{array}{l}\text { Preferred dentist } \\
\text { Female }\end{array}$ & $87(88.8 \%)$ & $81(79.4 \%)$ & $\mathbf{0 . 0 7 1}$ \\
Male & $11(11.2 \%)$ & $21(20.6 \%)$ & \\
\hline
\end{tabular}

Chi-square test.

The majority of the children in this study reported that they liked their first visit to dentist, which is consistent with the results of AlSarheed [7] and Mittal and Sharma [2]. Mittal and Sharma [2] indicated that younger children had more negative perceptions than older children because younger children could not comply satisfactorily. Klein [13] and Oppenheim and Frankl [14] reported similar findings. Similarly, the children who were afraid of a dentist were significantly younger than those who were not.

Dental anxiety is likely predictive of the occurrence of dental caries. We found a significant difference between $\mathrm{dmft} / \mathrm{DMFT}$ values and dental fear; the mean $\mathrm{dmft}$ and DMFT scores were significantly higher in children who had dental fear $(P<0.01, P<0.05)$. Conversely, Taani et al. [3] found no correlation between "general dental fear" and DMFT scores.

Mistry and Tahmassebi [11] reported a significant difference in the preference of the participants for the gender of their dental health care provider: male participants favored male students and females preferred female students. In our study, $84 \%$ of the children preferred to be treated by a female dentist, regardless of the child's gender.

Proper dress and the use of protective clothing protect both patients and health care providers from infectious diseases. We found that $70.5 \%$ of the children preferred that dentists wear masks. Similarly, Shulmam and Brehm [15] reported that $70 \%$ preferred that dentists wore a mask during dental treatment.

\section{Conclusion}

Dental anxiety likely predicts dental caries and may be a risk factor thereof. This study identified a significant difference between $\mathrm{dmft} / \mathrm{DMFT}$ values and dental fear. In addition, children have strong preferences regarding the appearance of their dentist and dental clinics. To promote dental health, all members of the dental profession must be aware of patient perceptions, preferences, and fears in order to meet patient needs and provide quality care in a manner that is comforting and reduces anxiety.

\section{Conflict of Interests}

The authors declare that there is no conflict of interests regarding the publication of this paper. 


\section{Acknowledgments}

Ebru Osmanoğlu Akyol helped the authors with the statistical analysis. There was no sponsor for their study and statistical analysis. Everything was billed to the names of the authors.

\section{References}

[1] W. A. Brill, “The effect of restorative treatment on children's behavior at the first recall visit in a private pediatric dental practice," The Journal of clinical pediatric dentistry, vol. 26, no. 4, pp. 389-393, 2002.

[2] R. Mittal and M. Sharma, "Assessment of psychological effects of dental treatment on children," Contemp Clin Dent, vol. 3, supplement 1, pp. S2-S7, 2012.

[3] D. Q. Taani, S. S. El-Qaderi, and E. S. Abu Alhaija, "Dental anxiety in children and its relationship to dental caries and gingival condition," International journal of dental hygiene, vol. 3, no. 2, pp. 83-87, 2005.

[4] A. Gustafsson, "Dental behaviour management problems among children and adolescents-a matter of understanding? Studies on dental fear, personal characteristics and psychosocial concomitants," Swedish Dental Journal, vol. 202, pp. 2-46, 2010.

[5] A. Gustafsson, K. Arnrup, A. G. Broberg, L. Bodin, and U. Berggren, "Psychosocial concomitants to dental fear and behaviour management problems," International Journal of Paediatric Dentistry, vol. 17, no. 6, pp. 449-459, 2007.

[6] K. Salem, M. Kousha, A. Anissian, and A. Shahabi, "Dental fear and concomitant factors in 3-6-year-old Children," Journal of Dental Research, Dental Clinics, Dental Prospects, vol. 6, no. 270, 74 pages, 2012.

[7] M. AlSarheed, “Children's perception of their dentists," European Journal of Dentistry, vol. 5, no. 2, pp. 186-190, 2011.

[8] S. Lahti, H. Tuutti, and E. Honkala, "The relationship of parental dental anxiety and child's caries status," ASDC journal of dentistry for children, vol. 56, no. 3, pp. 191-195, 1989.

[9] I. Alvesalo, H. Murtomaa, P. Milgrom, A. Honkanen, M. Karjalainen, and K. M. Tay, "The Dental Fear Survey Schedule: a study with Finnish children," International Journal of Paediatric Dentistry, vol. 3, no. 4, pp. 193-198, 1993.

[10] Oral Health Surveys: Basic Methods, World Health Organization, Geneva, Switzerland, 4th edition, 1997.

[11] D. Mistry and J. F. Tahmassebi, "Children's and parents' attitudes towards dentists' attire," European Archives of Paediatric Dentistry, vol. 10, no. 4, pp. 237-240, 2009.

[12] J. J. McCarthy, M. C. McCarthy, and R. E. Eilert, "Children's and parents' visual perception of physicians," Clinical Pediatrics, vol. 38, no. 3, pp. 145-152, 1999.

[13] H. Klein, "Psychological effects of dental treatment on children of different ages," Journal of dentistry for children, vol. 34, no. 1 , pp. 30-36, 1967.

[14] M. N. Oppenheim and S. N. Frankl, "A behavioral analysis of the preschool child when introduced to dentistry or hygienist," Journal of Dentistry for Children, vol. 38, pp. 317-325, 1971.

[15] E. R. Shulmam and W. T. Brehm, "Dental clinical attire and infection-control procedures: Patients' attitudes," Journal of the American Dental Association, vol. 132, no. 4, pp. 508-516, 2001. 


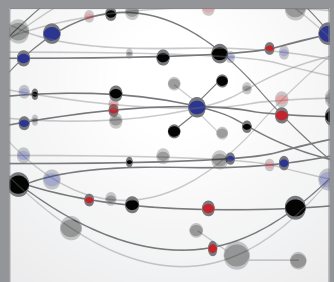

The Scientific World Journal
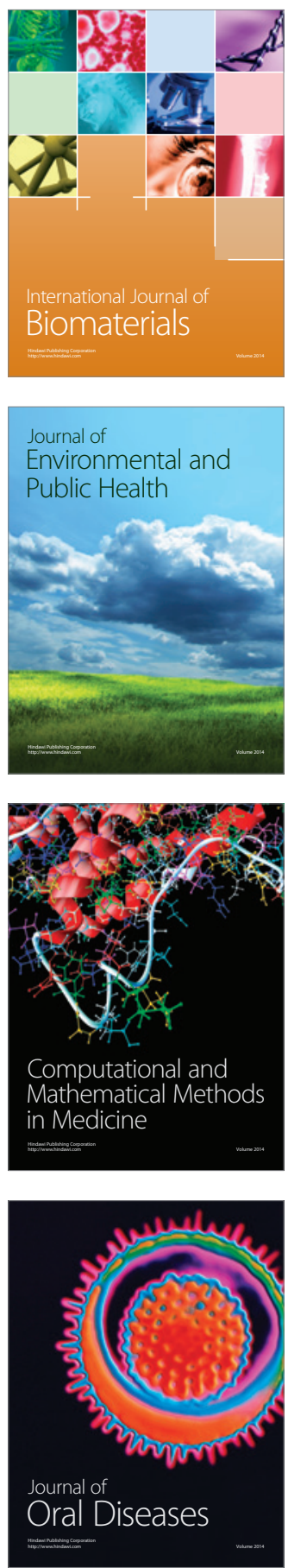
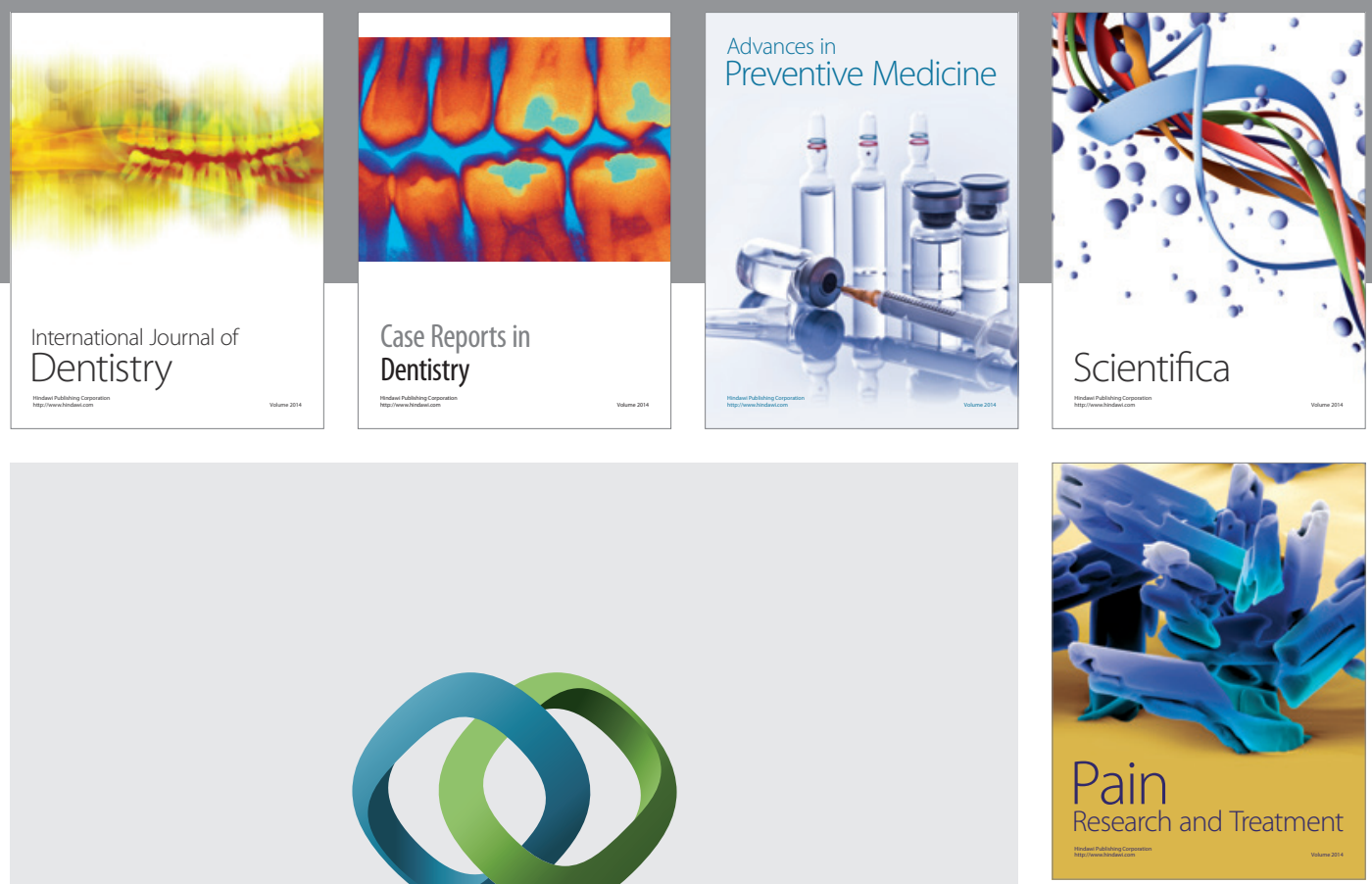

\section{Hindawi}

Submit your manuscripts at

http://www.hindawi.com
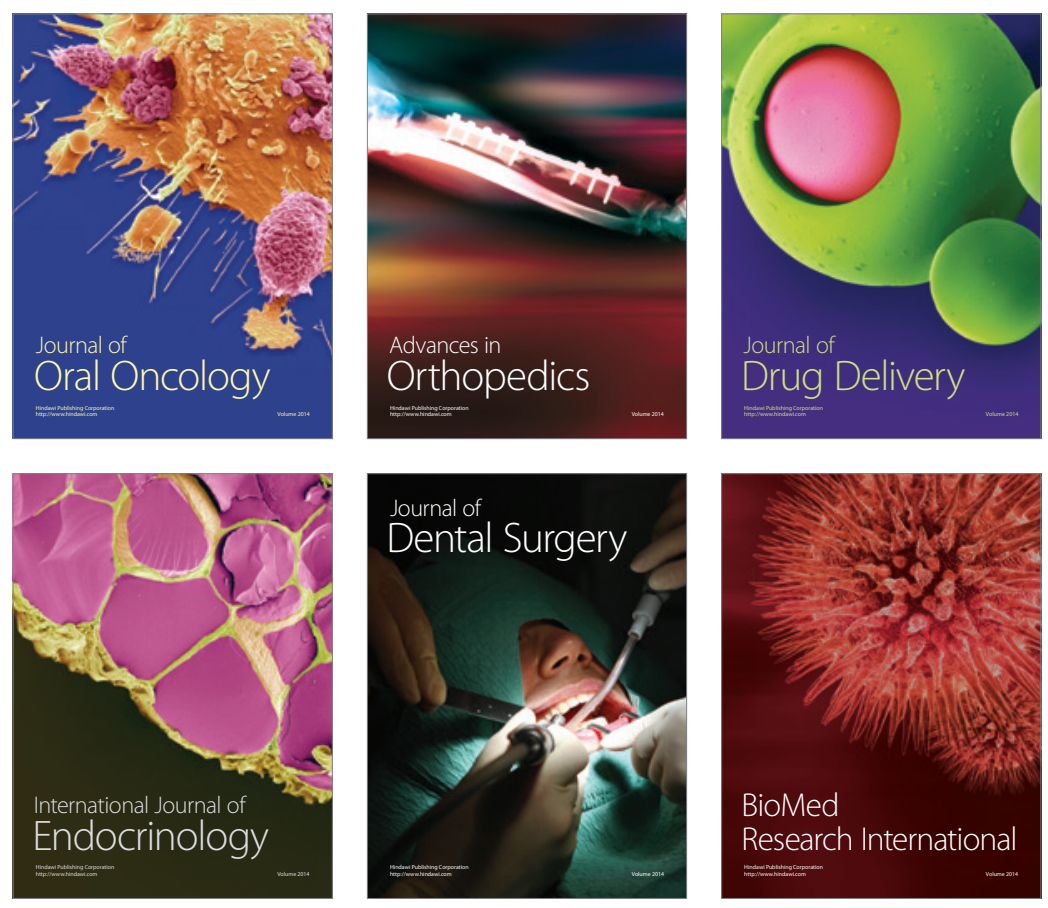

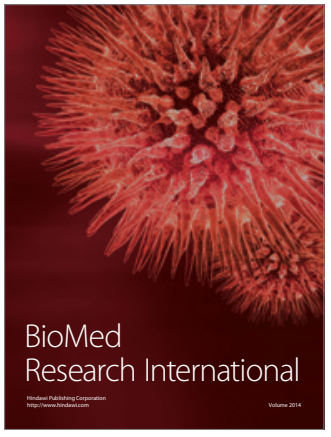

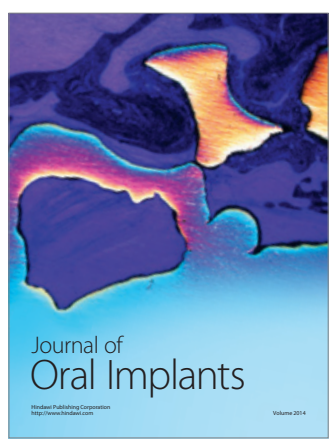
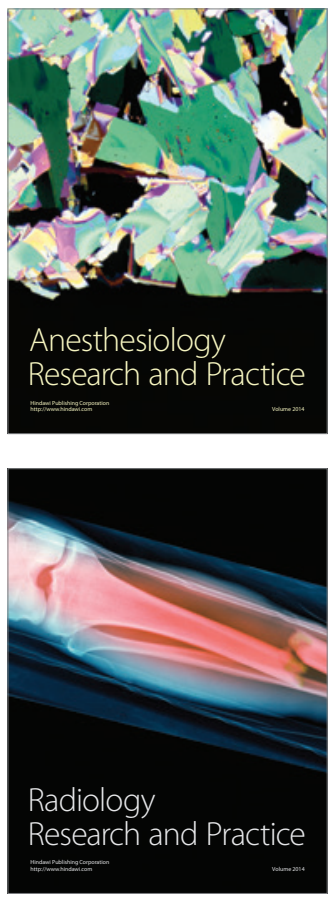